\title{
Impact of hypertrophic pulmonary osteoarthropathy on patients with lung cancer
}

This article was published in the following Dove Press journal:

OncoTargets and Therapy

25 October 2017

Number of times this article has been viewed

\section{Yu-Hung Fang' \\ Chien-Chin $\mathrm{Hsu}^{2}$ \\ Meng-Jer Hsieh ${ }^{3,4}$ \\ Ming-Szu Hung ${ }^{1,5,6}$ \\ Ying-Huang Tsai ${ }^{1,3}$ \\ Yu-Ching Lin ${ }^{1,4-6}$}

'Department of Pulmonary and Critical Care Medicine, Division of

Thoracic Oncology, Chang Gung

Memorial Hospital, Puzi, ${ }^{2}$ Department

of Nuclear Medicine, Chang Gung

Memorial Hospital, Kaohsiung

Branch, Kaohsiung, ${ }^{3}$ Department

of Respiratory Therapy, College of

Medicine, Chang Gung University,

Guishan, ${ }^{4}$ Department of Pulmonary

and Critical Care Medicine, Division

of Pulmonary Infection and Critical

Care Medicine, Chang Gung Memorial

Hospital, ${ }^{5}$ Department of Respiratory

Care, Chang Gung University

of Science and Technology, Puzi,

${ }^{6}$ Department of Medicine, College of

Medicine, Chang Gung University,

Guishan, Taiwan, Republic of China

Correspondence: Yu-Ching Lin Department of Pulmonary and Critical

Care Medicine, Division of Thoracic

Oncology, Chang Gung Memorial

Hospital, Chiayi Branch, No 6, W. Sec.,

Jiapu Rd., Puzi, Chiayi County 61363,

Taiwan, Republic of China

Tel +8865362 I000 ext 2762

Fax +88653623005

Email lin0927@cgmh.org.tw
Purpose: Hypertrophic pulmonary osteoarthropathy (HPOA) is a rare disease that most commonly occurs secondary to lung cancer. However, the clinical significance of HPOA remains unclear. The aim of this study was to evaluate the impact of HPOA on patients with lung cancer in Taiwan.

Patients and methods: Data regarding lung cancer patients who demonstrated findings of HPOA on bone scintigraphy between 2010 and 2016 were retrospectively analyzed. Pathological confirmation of cases was conducted at Chiayi and Kaohsiung Chang Gang Memorial Hospital. Clinical characteristics, including gender, smoking status, histology subtype, clinical stage, and epidermal growth factor receptor (EGFR) status were investigated.

Results: We identified 69 lung cancer patients with typical HPOA findings on bone scintigraphy. Among them, 56 were male $(81.2 \%)$ and 51 were ex-smokers or current smokers $(73.9 \%)$ Adenocarcinoma was the most common histology subtype ( $n=42,60.9 \%)$. Of 34 patients subjected to EGFR mutation analysis, only 4 (11.8\%) had EGFR-tyrosine kinase inhibitor (EGFR-TKI)-sensitive mutations.

Conclusion: Male, smoking, and adenocarcinoma were the most common clinical characteristics of lung cancer patients with HPOA in our cohort. However, the proportion of EGFR-TKIsensitive mutation cases was extremely low.

Keywords: EGFR, lung cancer, hypertrophic pulmonary osteoarthropathy, bone scintigraphy

\section{Introduction}

Hypertrophic pulmonary osteoarthropathy (HPOA) is a condition that is characterized by finger clubbing, joint pain and swelling, and periosteal proliferation of the long bones and largely affects patients with underlying pulmonary diseases. The most common cause of secondary HPOA is pulmonary malignancy. ${ }^{1}$ The incidence of HPOA among lung cancer patients ranged from $0.72 \%$ to $17 \% .{ }^{2,3}$ However, currently, the exact mechanism and molecular pathogenesis of HPOA remain unclear. The literature presents two hypotheses: a neurogenic pathway and a biochemical pathway. A previous study reported that a unilateral vagotomy conducted to interrupt the afferent neural pathway over the affected side of the malignancy effectively relieved joint pain in patients with HPOA. ${ }^{4}$ Therefore, a neural pathway was considered to be involved in the pathogenesis of HPOA. However, some researchers reported that abnormal production of hypoxiainduced agents, including platelet-derived growth factor (PDGF), prostaglandin E2 (PGE2), and vascular endothelial growth factor (VEGF) in patients with HPOA, was observed. ${ }^{5}$ Therefore, subsequently, patients with primary familial hypertrophic osteoarthropathy and neonates with congenital heart disease were prescribed long-term PGE2 injections owing to the possibility of a biochemical pathway. ${ }^{6,7}$ 
The discovery of the epidermal growth factor receptor (EGFR) mutation as a major driver oncogene in certain lung adenocarcinomas is one of the most important advancements in lung cancer treatment over the past 20 years. Because HPOA is associated with higher serum levels of PDGF, PGE2, and VEGF, and because these factors could activate the EGFR pathway, one can assume that the tumor cells in lung cancer patients with HPOA may be less dependent on the EGFR pathway. However, information regarding EGFR status in lung cancer patients with HPOA is scarce. Therefore, the present study examined the incidence, clinical characteristics, and EGFR mutation status of lung cancer patients with HPOA in Taiwan.

\section{Methods}

\section{Patients}

This study included patients with pathologically confirmed primary lung cancer who underwent bone scintigraphy between January 2010 and December 2016 for staging. The pathological analyses were conducted at Chiayi and Kaohsiung Chang Gang Memorial Hospital, two large teaching hospitals in Taiwan. For the standard bone scintigraphy, patients received a parenteral injection with $740 \mathrm{MBq}(20 \mathrm{mCi}) \mathrm{Tc}-99 \mathrm{~m}-$ hydroxymethylene diphosphate; static images were obtained after 3-6 hours. Medical records were reviewed to exclude major causes of HPOA other than lung cancer. For the purpose of the study, HPOA was defined as typical diffuse, symmetri$\mathrm{cal}$, and increased linear uptake in the cortical margins of the long tubular bones on bone scintigraphy.

We retrospectively reviewed clinical data including histological type, age at diagnosis, gender, smoking history, EGFR mutation subtype, and clinical stage. Clinical stage was evaluated independently by experienced radiologists according to the Cancer Staging Manual of the American Joint Committee on Cancer 7th edition and confirmed by a multidisciplinary team committee. The institutional review board of Chang Gung Memorial Hospital approved this study and deemed written informed consent not necessary due to the retrospective nature of this study (201700522B0). Nonetheless, patient anonymity and confidentiality were maintained throughout the study.

\section{EGFR mutation analysis}

We extracted tumor DNA from formalin-fixed, paraffinembedded tissue with the Qiagen QIAamp DNA Mini Kit (QIAGEN ${ }^{\circledR}$, Crawley, UK). EGFR mutations were analyzed via direct sequencing and/or the Scorpion Amplification Refractory Mutation System-based EGFR mutation detection kit (Therascreen EGFR RGQ PCR kit; QIAGEN), which detects 29 mutations across the EGFR gene. The analyses were performed at 3 central laboratories at the Linkou, Kaohsiung, and Chiayi Chang Gang Memorial Hospital.

\section{Results}

Between January 2010 and December 2016, a total of 42,314 patients underwent bone scintigraphy. Among them, $93 \mathrm{dem}-$ onstrated typical HPOA findings on bone scintigraphy, and 24 were excluded because of underlying diseases other than lung cancer (eg, hepatocellular carcinoma, nasopharyngeal carcinoma, soft tissue sarcoma, esophageal cancer, thymic carcinoma, cervical cancer, breast cancer, cholangiocarcinoma, melanoma, hypercalcemia, and liver cirrhosis). Moreover, 69 (74.19\%) patients were diagnosed with lung cancer-related HPOA. Concurrently, 5,386 patients were diagnosed with lung cancer at the Chiayi and Kaohsiung Chang Gang Memorial Hospital, yielding an incidence rate of lung cancer patients with HPOA of around $1.28 \%$.

The clinical characteristics of the 69 lung cancer patients with HPOA are listed in Table 1. Among them, 56 were male $(81.2 \%)$ and 51 were ex-smokers or current smokers (73.9\%). The median age of the male patients was 61 years, which was older than that of the female patients (53 years). Adenocarcinoma was the most common histology subtype

Table I Clinical characteristics of lung cancer patients with HPOA

\begin{tabular}{|c|c|c|c|}
\hline Characteristics & $\begin{array}{l}\text { Male } \\
\mathrm{N}=56 \text { (\%) }\end{array}$ & $\begin{array}{l}\text { Female } \\
N=13 \text { (\%) }\end{array}$ & $\begin{array}{l}\text { Total } \\
\mathrm{N}=69\end{array}$ \\
\hline \multicolumn{4}{|l|}{ Smoker } \\
\hline Never & $7(12.5)$ & II (84.6) & 18 \\
\hline Ex- or current & $49(87.5)$ & $2(15.4)$ & 51 \\
\hline \multicolumn{4}{|l|}{ Histology } \\
\hline Adenocarcinoma & $35(62.5)$ & $7(53.8)$ & 42 \\
\hline Squamous cell carcinoma & II (19.6) & I (7.7) & 12 \\
\hline Others & 10 & 5 & 15 \\
\hline Adenosquamous & $4(7.1)$ & $2(15.4)$ & 6 \\
\hline Large-cell carcinoma & $3(5.3)$ & $2(15.4)$ & 5 \\
\hline Sarcomatoid carcinoma & $2(3.6)$ & I (7.7) & 3 \\
\hline Small-cell carcinoma & $\mathrm{I}(\mathrm{I} .8)$ & $0(0)$ & I \\
\hline \multicolumn{4}{|l|}{ Clinical stage } \\
\hline I & $0(0)$ & I (7.7) & I \\
\hline ॥ & $5(8.9)$ & I (7.7) & 6 \\
\hline Illa & $6(10.7)$ & I (7.7) & 7 \\
\hline IIllb & $7(12.5)$ & I (7.7) & 8 \\
\hline IV & $38(67.9)$ & $9(69.2)$ & 47 \\
\hline EGFR & 26 & 8 & 34 \\
\hline Wild type & $23(88.5)$ & $6(75)$ & 29 \\
\hline Exon 20 insertion & I (3.8) & $0(0)$ & I \\
\hline Eonx 2I L858R & $2(7.7)$ & $0(0)$ & 2 \\
\hline Exon 19 deletion & $0(0)$ & $2(25)$ & 2 \\
\hline
\end{tabular}

Abbreviations: HPOA, hypertrophic pulmonary osteoarthritis; EGFR, epidermal growth factor receptor. 
Table 2 Treatment outcome of HPOA patients with EGFR sensitive mutation

\begin{tabular}{llllllll}
\hline No & Gender & Age & EGFR & Stage & TKIs & PFS (m) & OS $(\mathbf{m})$ \\
\hline $\mathrm{I}$ & Female & 77 & L858R & Ib & Gefitinib & 2.5 & $36.0 *$ \\
2 & Female & 53 & Exon 19 deletion & IV & Gefitinib & 5.9 & 52.6 \\
3 & Male & 68 & Exon 19 deletion & Illb & Erlotinib & 8.2 & 29.0 \\
\hline
\end{tabular}

Note: *From cancer recurrence to patient deceased.

Abbreviations: (m), months; No, number; EGFR, epidermal growth factor receptor; HPOA, hypertrophic pulmonary osteoarthropathy; TKIs, tyrosine kinase inhibitors; PFS, progression-free survival; OS, overall survival.

$(n=42,60.9 \%)$, followed by squamous cell carcinoma $(n=12$; $17.4 \%)$. In addition, 55 (79.7\%) patients had stage IIIb or IV disease and only $7(10.1 \%)$ had stage I or II disease. Of the 34 patients with adenocarcinoma $(34 / 42,81.0 \%)$ who were subjected to EGFR mutation analyses, only 4 (11.8\%) had EGFR-tyrosine kinase inhibitor (EGFR-TKI)-sensitive mutations, 2 (5.9\%) had exon 21 point mutations (L858R), and $2(5.9 \%)$ had exon 19 deletions. Among patients with EGFR-TKI-sensitive mutations, 1 refused further treatment and was lost to follow-up. One woman with stage Ib disease underwent surgical resection but did not receive adjuvant chemotherapy. Recurrent lung cancer with bone metastasis was detected 14.6 months later in January 2012 in 2 patients with stage IIIb and IV lung cancer who received first-line EGFRTKIs. The treatment outcomes are summarized in Table 2.

\section{Discussion}

Most of the HPOA patients in our study were male and/or ex-smokers or current smokers, which is consistent with the results of previous studies. Moreover, the incidence of EGFRTKI-sensitive mutations in this population was extremely low. To our knowledge, this is the first study to identify an association between HPOA and EGFR mutation status.

We systemically reviewed previously reported case series and selected those involving more than 10 patients for comparison (Table 3). The incidence of HPOA in lung cancer patients ranged from $0.8 \%$ to $4.5 \%$ according to published reports, although Morgan et $\mathrm{al}^{3}$ reported an incidence rate of $17 \%$ in 1996 . In the present study, the incidence of HPOA among lung cancer patients was around $1.2 \%$, which is similar to that demonstrated by Qian and Qin. ${ }^{18}$ This can be explained by the similarity in the race-ethnicity of the cohort and geographic location between the studies.

According to previous reports in Taiwan, ${ }^{8-10}$ only $54.7 \%-65.5 \%$ of patients with lung cancer are male and $43 \%-45 \%$ patients are smokers. The molecular mechanism of HPOA is not yet completely well established. Some hypoxia-associated cytokines or growth factors, including PDGF, PGE2, and VEGF, were thought to be involved in the development of periostosis and digital clubbing in different diseases including right to left shunt, ${ }^{11}$ abdominal aortic aneurysm, ${ }^{15}$ and ulcerative colitis. ${ }^{16}$ Protein products of the 15-hydroxyprostaglandin dehydrogenase (HPGD) gene and solute carrier organic anion transporter family member $2 \mathrm{~A} 1$ gene (SLCO2A1) convert PGE2 into its metabolite 13,14dihydro-15-ketoprostaglandin E2. Mutation of the HPGD ${ }^{12}$ and SLCO2A1 $1^{13}$ genes has been reported to be associated with familial primary hypertrophic osteoarthritis. Since smoking causes elevation of serum levels of PGE2 and increase major metabolites concentration in urine sample, ${ }^{14,17}$ it may be associated with periostosis and digital clubbing among male lung cancer patients. ${ }^{14}$

Adenocarcinoma was the most common histological subtype in all the lung cancer patients irrespective of gender: $60.5 \%$ and $81.4 \%$ for male and female lung cancer patients, respectively. ${ }^{8}$ Adenocarcinoma was also the most common histological type in all lung cancer patients with HPOA. In this study, $42(60.9 \%)$ HPOA patients had adenocarcinoma, and 12 (17.4\%) had squamous cell carcinoma. However, among the lung cancer patients with HPOA,

Table 3 Characteristics of lung cancer patients with HPOA in previous studies

\begin{tabular}{|c|c|c|c|c|c|c|c|}
\hline Author & Year & $\mathbf{N}$ & Incidence & Male & Smoker & $\begin{array}{l}\text { Adenocarcinoma } \\
\text { histology }\end{array}$ & EGFR M+ \\
\hline This study & 2017 & 69 & $1.28 \%$ & $81.2 \%$ & $73.9 \%$ & $60.8 \%$ & $11.8 \%$ \\
\hline Qian and Qin ${ }^{18}$ & 2014 & 115 & $1.87 \%$ & $91 \%$ & $76 \%$ & $48 \%$ & NM \\
\hline Ito et $\left.a\right|^{2}$ & 2010 & 19 & $0.72 \%$ & $89.4 \%$ & $94.7 \%$ & $52.6 \%$ & NM \\
\hline Izumi et al ${ }^{19}$ & 2010 & 55 & $4.5 \%$ & $70.9 \%$ & NM & $45 \%$ & NM \\
\hline Morgan et $\mathrm{al}^{3}$ & 1996 & 28 & $17 \%$ & $78.5 \%$ & NM & $17 \%$ & NM \\
\hline Segal and Mackenzie ${ }^{20}$ & 1982 & 16 & $0.8 \%$ & $68.8 \%$ & $100 \%$ & $38 \%$ & NM \\
\hline
\end{tabular}

Abbreviations: N, patient numbers; EGFR, epidermal growth factor receptor; $M+$, with sensitive mutation; NM, not mentioned. 
the incidence of adenocarcinoma was comparable in males (62.5\% vs $60.5 \%)$, but much lower in females $(53.8 \%$ vs $81.4 \%$ ). Compared with previously published HPOA studies, ${ }^{2,3,18-20}$ the percentage of adenocarcinoma was much higher in our series, which could be attributable to geographic and/or race-ethnic reasons, or just the representation of the increasing trend in lung adenocarcinoma globally. ${ }^{21,22}$

The prevalence of EGFR mutations is particularly high among East Asian patients with non-small-cell lung cancer, especially among female never smokers. ${ }^{23}$ In Taiwan, the incidence of EGFR-TKI-sensitive mutations among male smokers ranges from $25 \%$ to $57 \%$ and more than $60 \%$ among female never smokers. ${ }^{10,23,24}$ In this study, the proportion of EGFR-TKI-sensitive mutations was extremely low among patients with HPOA (males, 7.7\%; females, 25\%). This finding may indicate different underlying pathogeneses among lung cancer patients with HPOA. The EGFR mutation may therefore not be the major driver mutation among these patients. Since HPOA is typically observed in the early stages of lung cancer, factors involved in the pathogenesis, such as PGE2, could be the key factors. PGE2 upregulates the EGFR-stimulated Akt and ERK pathway ${ }^{25,26}$ and is associated with lung carcinogenesis and resistance to first-line EGFRTKI. ${ }^{27}$ Further studies should be conducted to evaluate serum PGE2 level and its interaction with EGFR mutation status. Previous studies reported comparable survival rates between lung cancer patients with and without HPOA, ${ }^{3}$ but lacked data regarding the efficacy of EGFR-TKIs. In our study, we observed shorter progression-free survival and similar overall survival among these 3 patients with EGFR-sensitive mutation who received EGFR-TKIs compared with that reported in previous first-line EGFR-TKIs in TKI-related studies. Further studies should be interesting for evaluation of the treatment response to EGFR-TKIs and efficacy of EGFRTKIs among non-small-cell lung cancer patients with HPOA harboring sensitive EGFR mutations.

This present study has certain limitations because of its retrospective design. The patients were included on the basis of the presence of typical findings of HPOA on bone scintigraphy rather than clinical presentation. Therefore, we may have not included all lung cancer patients with HPOA, resulting in an underestimation of the incidence. Owing to the limited number of patients, we could not confirm the impact of HPOA on the efficacy of first-line EGFR-TKI treatment. According to previous studies, bone scintigraphy is more sensitive for the detection of the extent of HPOA than radiography. Upon diagnosis of lung cancer, every patient undergoes an initial bone scintigraphy for cancer staging.
We usually do not order plain films of the bone for lung cancer patients. Therefore, in contrast with other retrospective studies, we analyzed only bone scintigraphy images but not plain radiography films. In addition, the patients may have had more than one disease other than lung cancer that could have caused periostosis and digital clubbing such as chronic obstructive pulmonary disease, liver cirrhosis, pulmonary tuberculosis, aortic aneurysm, and/or ulcerative colitis. We could not differentiate lung cancer from other diseases based on bone scintigraphy findings. Moreover, owing to the retrospective nature of this analysis we could not confirm whether those certain diseases coexisted or clarify the chronological order of the diseases and lung cancer. Finally, the mechanisms that predispose lung cancer patients to HPOA were not investigated.

\section{Conclusion}

This is the first retrospective study to evaluate the clinical significance of HPOA and EGFR mutation status in lung cancer patients. Similar to previous studies, male, smoking, and adenocarcinoma histology were the most common clinical characteristics. Moreover, the proportion of EGFR-TKIsensitive mutations was extremely low among the included patients. Further studies regarding the mechanisms and impact of HPOA and EGFR status in lung adenocarcinoma patients are warranted.

\section{Acknowledgments}

We would like to thank the cancer center at Kaohsiung Chang Gang Memorial Hospital for their assistance in the data collection. This study is supported by funding from Chang Gung Medical Foundation (CMRPG690351).

\section{Disclosure}

The authors report no conflicts of interest in this work.

\section{References}

1. Vandemergel X, Blocklet D, Decaux G. Periostitis and hypertrophic osteoarthropathy: etiologies and bone scan patterns in 115 cases. Eur J Intern Med. 2004;15(6):375-380.

2. Ito T, Goto K, Yoh K, et al. Hypertrophic pulmonary osteoarthropathy as a paraneoplastic manifestation of lung cancer. J Thorac Oncol. 2010; 5(7):976-980.

3. Morgan B, Coakley F, Finlay DB, Belton I. Hypertrophic osteoarthropathy in staging skeletal scintigraphy for lung cancer. Clin Radiol. 1996; 51(10):694-697.

4. Treasure T. Hypertrophic pulmonary osteoarthropathy and the vagus nerve: an historical note. J R Soc Med. 2006;99(8):388-390.

5. Yap FY, Skalski MR, Patel DB, et al. Hypertrophic osteoarthropathy: clinical and imaging features. Radiographics. 2017;37(1):157-195.

6. Giancane G, Diggle CP, Legger EG, et al. Primary hypertrophic osteoarthropathy: an update on patient features and treatment. J Rheumatol. 2015;42(11):2211-2214. 
7. Letts M, Pang E, Simons J. Prostaglandin-induced neonatal periostitis. J Pediatr Orthoped. 1994;14(6):809-813.

8. Hsu LH, Chu NM, Liu CC, et al. Sex-associated differences in non-small cell lung cancer in the new era: is gender an independent prognostic factor? Lung Cancer. 2009;66(2):262-267.

9. Wang BY, Huang JY, Cheng CY, Lin CH, Ko J, Liaw YP. Lung cancer and prognosis in Taiwan: a population-based cancer registry. $J$ Thorac Oncol. 2013;8(9):1128-1135.

10. Hsiao SH, Lin SE, Chou YT, et al. Histological subtype and smoking status, but not gender, are associated with epidermal growth factor receptor mutations in non-small-cell lung cancer. Mol Clin Oncol. 2014; 2(2):252-258.

11. Yao Q, Altman RD, Brahn E. Periostitis and hypertrophic pulmonary osteoarthropathy: report of 2 cases and review of the literature. Semin Arthritis Rheum. 2009;38(6):458-466.

12. Yuan L, Chen L, Liao RX, et al. A common mutation and a novel mutation in the HPGD gene in nine patients with primary hypertrophic osteoarthropathy. Calcif Tissue Int. 2015;97(4):336-342.

13. Ayoub N, Al-Khenaizan S, Sonbol H, Albreakan R, AlSufyani M, AlBalwi M. A novel homozygous mutation in the SLCO2A1 gene is associated with severe primary hypertrophic osteoarthropathy phenotype in a Saudi patient. Int J Dermatol. 2015;54(6):e233-e235.

14. Kozak KR, Milne GL, Bentzen SM, Yock TI. Elevation of prostaglandin E2 in lung cancer patients with digital clubbing. $J$ Thorac Oncol. 2012;7(12):1877-1878.

15. Dilme JF, Sola-Villa D, Bellmunt S, et al. Active smoking increases microsomal PGE2-synthase-1/PGE-receptor-4 axis in human abdominal aortic aneurysms. Mediat Inflamm. 2014;2014:316150.

16. Liu ES, Ye YN, Shin VY, Wu WK, Wong BC, Cho CH. Interaction of cigarette smoking with cyclooxygenase- 2 on ulcerative colitisassociated neoplasia in mice. Cancer Invest. 2007;25(8):750-757.

17. Gross ND, Boyle JO, Morrow JD, et al. Levels of prostaglandin E metabolite, the major urinary metabolite of prostaglandin E2, are increased in smokers. Clin Cancer Res. 2005;11(16):6087-6093.
18. Qian X, Qin J. Hypertrophic pulmonary osteoarthropathy with primary lung cancer. Oncol Lett. 2014;7(6):2079-2082.

19. Izumi M, Takayama K, Yabuuchi H, Abe K, Nakanishi Y. Incidence of hypertrophic pulmonary osteoarthropathy associated with primary lung cancer. Respirology. 2010;15(5):809-812.

20. Segal AM, Mackenzie AH. Hypertrophic osteoarthropathy: a 10-year retrospective analysis. Semin Arthritis Rheum. 1982;12(2):220-232.

21. Lortet-Tieulent J, Soerjomataram I, Ferlay J, Rutherford M, Weiderpass E, Bray F. International trends in lung cancer incidence by histological subtype: adenocarcinoma stabilizing in men but still increasing in women. Lung Cancer. 2014;84(1):13-22.

22. Chang JS, Chen LT, Shan YS, et al. Comprehensive analysis of the incidence and survival patterns of lung cancer by histologies, including rare subtypes, in the era of molecular medicine and targeted therapy: a nation-wide cancer registry-based study from Taiwan. Medicine. 2015;94(24):e969.

23. Midha A, Dearden S, McCormack R. EGFR mutation incidence in non-small-cell lung cancer of adenocarcinoma histology: a systematic review and global map by ethnicity (mutMapII). Am J Cancer Res. 2015; 5(9):2892-2911.

24. Hsu $\mathrm{CH}$, Tseng $\mathrm{CH}$, Chiang $\mathrm{CJ}$, et al. Characteristics of young lung cancer: analysis of Taiwan's nationwide lung cancer registry focusing on epidermal growth factor receptor mutation and smoking status. Oncotarget. 2016;7(29):46628-46635.

25. Dajani OF, Meisdalen K, Guren TK, et al. Prostaglandin E2 upregulates EGF-stimulated signaling in mitogenic pathways involving Akt and ERK in hepatocytes. J Cell Physiol. 2008;214(2):371-380.

26. Fernandez-Martinez AB, Lucio Cazana FJ. Epidermal growth factor receptor transactivation by intracellular prostaglandin E2-activated prostaglandin E2 receptors. Role in retinoic acid receptor-beta upregulation. Biochim Biophys Acta. 2013;1833(9):2029-2038.

27. Gomperts BN, Spira A, Massion PP, et al. Evolving concepts in lung carcinogenesis. Semin Respir Crit Care Med. 2011;32(1):32-43.
OncoTargets and Therapy

\section{Publish your work in this journal}

OncoTargets and Therapy is an international, peer-reviewed, open access journal focusing on the pathological basis of all cancers, potential targets for therapy and treatment protocols employed to improve the management of cancer patients. The journal also focuses on the impact of management programs and new therapeutic agents and protocols on

\section{Dovepress}

patient perspectives such as quality of life, adherence and satisfaction. The manuscript management system is completely online and includes a very quick and fair peer-review system, which is all easy to use. Visit http://www.dovepress.com/testimonials.php to read real quotes from published authors. 